Revista de Estudios Histórico-Jurídicos

[Sección derechos de la antigüedad salvo el romano]

XXXIX (Valparaíso, Chile, 2017)

[pp. 37 - 57]

\title{
El CONTROL CONSTITUCIONAL DE LAS LEYES EN ATENAS
}

[The constitutional review of laws in Athens]

\author{
Priscila Machado Martins* \\ Universidad Central de Chile
}

\section{RESUMEN}

Este artículo pretende entregar una referencia histórica acerca de lo que se puede entender como un tipo de control de las leyes en la Atenas clásica. Si bien puede ser impropio hablar de justicia constitucional en la Antigüedad, específicamente en la Grecia clásica del siglo $\mathrm{V}$ a. C., las instituciones atenienses de la "graphêparanomôn" y la "graphê nomon", correspondían a acciones que buscaban un efecto muy similar al de los instrumentos de control de constitucionalidad de las leyes en el día de hoy, las que además de servir como herramientas que tienden a evitar las antinomias, implicaban una interesante fuente para la comprensión actual de los conceptos de Constitución y Justicia Constitucional.

Palabras clave

Control delas leyes-GraphéParanomon - Norma inconstitucional - Cosa Juzgada constitucional.

\section{ABSTRACT}

This paper pretends to provide a historical reference about what can be understood as a kind of constitutional reviews of laws in classical Athens. While may be improper to talk about constitutional justice in Ancient Times, specifically in classical Greece, the athenian's institutions of graphéparanomon and graphénomon, corresponded to actions that seeking a very similar effect to the instruments of the constitutional review of the laws, today, which also to serve as tool that tend to avoid normatives contradictions, involved an interesting source of the current concepts of Constitution and Constitutional Justice.

\section{KeYwords}

Judicial Review - GraphéParanomon - Inconstitucional rule - Constitutional res iudicata.

Recibido el 11 de diciembre de 2016 y aCEPTADo el 24 de julio de 2017

* Doctora en Derecho por la Pontificia Universidad Católica de Valparaíso, Chile; Profesora de Derecho Procesal y Derecho Procesal Constitucional en la Universidad Central de Chile. Dirección postal: Lord Cochrane No 417, Santiago, Chile. Correo electrónico: priscila. machado@ucentral.cl 


\section{INTRODUCCIÓN}

La universalización de la Justicia Constitucional es uno de los fenómenos jurídicos más relevantes de nuestro tiempo. Aunque es común que los estudiosos enfoquen su preocupación por el diseño de mecanismos de defensa del orden constitucional surgidos a partir de fines del siglo XVIII, lo cierto es que la idea de la defensa de un orden supremo es casi una constante en la historia de occidente, y en sus albores podemos encontrar algunos intentos de construcción y establecimiento de instituciones que controlaban la forma y el contenido de la producción legislativa. Un ejemplo de ello, es el caso de la Atenas clásica, en el cual encontramos interesantes atisbos de lo que podría comprenderse como un control constitucional de las leyes.

\section{La Concepción de Constitución en Atenas}

La concepción moderna de control de constitucionalidad cuenta con premisas que parten del pensamiento político ateniense, el cual ha definido las formas básicas del derecho constitucional y también ha trazado las primeras líneas sobre los cambios constitucionales, a pesar de no haber construido una teoría de la Constitución como ley fundamental. Aunque la figura del legislador ocupó lugar preponderante en su construcción jurídica, la polis griega creció marcada por una ausencia de consciencia acerca de su diseño constitucional similar al otorgado en la modernidad, sin embargo el mismo se encontraba aunque no escrito, implícito, y basado en las costumbres ${ }^{1}$.

Los pensadores griegos, en especial Platón y Aristóteles utilizaban el vocablo politeía - un substantivo proveniente del término póliç- para hablar de ciudadanía en dos sentidos, por un lado, como conjunto de ciudadanos, y por otro, como atributo abstracto de los mismos. No obstante, fue Aristóteles quien utilizó el término de modo restrictivo para designar la forma de gobierno de todos o de la mayoría, en oposición a su forma incorrecta, que denominó de demokratía ${ }^{2}$. Guzmán Brito destaca que Aristóteles "aprovechó el término para designar la forma de gobierno consistente en una mezcla de oligarquía y democracia, que él consideraba, en términos reales, como la mejor. En fin, y este es el sentido que nos interesa como quinto, ese vocablo aparece genéricamente aplicado a cualquier organización política, sentido en el cual se puede traducir precisamente por c on s t i t u c ión ${ }^{\prime 3}$.

Los pensadores griegos, entonces, entendían la constitución -la politeia-como la organización de la polis, configuración fundada en una ética natural de sus ciudadanos, pues la polis funcionaba de acuerdo con la idea de justicia que dominaba en la época clásica, de manera que la concepción griega de la Constitución

\footnotetext{
${ }^{1}$ Frankel Paul, Ellen; Miller JR., Fred D.; Paul, Jeffrey; What should constitutions do? (Cambridge, Cambridge University Press, 2011), pp. 26-27.

${ }^{2}$ Guzman Brito, Alejandro, El vocabulario histórico para la idea de constitución política, en Revista de Estudios Historicos-Jurídicos, 24 (2002), p. 269.

${ }^{3}$ Ibíd., p. 3.
} 
corresponde más bien a una noción ética, en la cual era la j u s t i c i a la que guiaba el uso y el desarrollo de las leyes, y por lo mismo, no es posible afirmar que el concepto de Constitución utilizado en la Atenas clásica, hacía referencia con la idea de estatuto que cumple el rol de ley fundamental del Estado ${ }^{4}$.

Por esto, es necesario realizar algunas aclaraciones de naturaleza terminológica y metodológica. Primordialmente, es menester recordar, que la palabra Constitución, en la actualidad, es utilizada en general para designar las reglas sobre la distribución del poder político, la organización de las competencias y la administración del poder, normas que suponen la separación de los poderes, y que garantizan derechos fundamentales de los individuos, que a la vez limitan el poder político, consagran la prevalencia del régimen democrático, y por último la supremacía de estas normas.

Si aceptásemos que la palabra Constitución solamente responde al delineamiento anteriormente señalado, se puede afirmar entonces, que en Grecia nunca hubo una verdadera Constitución, y lo mismo respecto todas aquellas constituciones anteriores a los finales del siglo XVIII, pues carecen de las mismas características 5 .

Por ello, corresponde aclarar que, para describir el trabajo de los legisladores clásicos, el término C o n s t i t u c i ó n debe ser utilizado en un sentido amplio, esto es, entendido como una composición de instituciones políticas, las que incluían normas detalladas de aspectos religiosos, de derecho de familia, de derecho penal y económico. Como ejemplo de esto, se puede mencionar el caso de Solón, quien creó un nuevo cuerpo legislativo, estableciendo el derecho a la apelación frente al tribunal de jurados, y reemplazando los requisitos de nacimiento y propiedad para votar en la Asamblea, provocando así, numerosos cambios sociales ${ }^{6}$. Con ello, podemos notar que el concepto de Constitución no estaba solamente vinculado con la estructura política, sino que también estaba relacionado con derechos sustanciales de importancia para los individuos de esta sociedad.

No obstante que los textos promulgados, los arreglos institucionales y los principios que gobernaban las ciudades-estados no eran exhaustivos, las polis, en muchos casos, fueron las primeras en sistematizar y determinar una estructura institucional escrita y reconocida por las generaciones posteriores como los fundamentos de su sistema jurídico y político ${ }^{7}$.

${ }^{4}$ Acerca de la expression Constitución: "The term is used here in the older sense, meaning the way that a government is constituted. There was in Athens no written constitution along the lines of the U.S. Constitution. The Athenian constitution, like the unwritten constitution of modern England, was a collection of customs, laws, institutions, and understanding, which were never reduced to a single document", en ROTHCHILD, John, Introduction to Athenian Democracy of the Fifth and Fourth Centuries BCE, en Wayne State University Law School, 32 (2007), p. 7; Cfr. GaGarin, Michael, Early greek law (Los Angeles, California Press, 1986), pp. 51-80.

5 SARTORI, Giovanni, Constitutionalism: a preliminary discussion, en American Political Science Review, 56 (1962), pp. 853 ss.

${ }^{6}$ OвER, J., The Athenian revolution: essays on ancient Greek democracy and political theory (Princeton, Princeton University Press, 1999), p. 38.

${ }^{7}$ GaGarin, Michael, cit. (n. 4), pp. 51-52; Cfr. LewIS, John David, Early Greek lawgivers (s.l., Bristol Class, 2007), pp. 41-42. 
A pesar de esta disyunción con el pensamiento constitucional moderno, la Grecia antigua, sin duda puede ofrecer una importante lección acerca de la relación entre Constitución, leyes y el procedimiento de decisión política ${ }^{8}$.

\section{El CONTROl DE LAS LEYeS EN AtenAS}

La graphéparanomon era una forma de acción legal que fue introducida en el sistema legal ateniense durante la democracia alrededor del año 415 a.C. La expresión griega significaba "demanda en contra de las cuentas contrarias a las leyes". Dicha acción podía ser impetrada tanto respecto leyes o decretos ya aprobados, o en un momento o estadio de tramitación anterior, desde que ya no fueran más que una propuesta de ley9. Tal herramienta procesal tuvo en los hechos, una doble función: en primer lugar proporcionar un mecanismo de revisión legal y de derogación de un decreto aprobado por la Ekklesía o Asamblea y, en segundo lugar, se utilizó con fines meramente políticos, en cuanto arma utilizada en contra de los rivales de tal naturaleza. A pesar de no haber antecedentes históricos sobre la creación de la graphéparanomon, es claro que esta institución fue idealizada y estructurada como una precaución o remedio en contra de la eventual toma precipitada de decisiones por la Asamblea popular, en particular en relación a las decisiones tomadas bajo la influencia de los demagogos ${ }^{10}$.

\section{Origen}

Los estudiosos generalmente vinculan el origen de la acción graphéparanomon a las reformas del año 462 a. C. promovidas por Efialtes, ya que en esta época, el Areópago se había reducido a un mero tribunal ordinario, para el conocimiento de casos como homicidios perdiendo el poder para supervisar las leyes ${ }^{11}$.

No obstante, no hay indicios de que la graphéparanomon haya sido utilizada antes de la Guerra del Peloponeso, y posiblemente haya sido creada en el año 415 a.C., con posterioridad a la última vez en que se utilizó el ostracismo en Atenas. Hansen explica que efectivamente, en el siglo $\mathrm{V}$ a. C., la principal arma utilizada

${ }^{8}$ Acerca de la importancia en el estudio del diseño constitucional ateniense: Cfr. LANNI, Adriaan; Vermeule, Adrian, Constitutional Design in the Ancient World, en Stanford Law Review, 11 (2011), p. 6.

${ }^{9}$ Cfr. MacDowell, Douglas M., Demosthenes the orator (New York, Oxford University Press, 2009), pp. 152 ss.

10 "The grapheparanomon was a legal procedure for challenging legislation passed by the Thenian Assembly as paranomos ("contrary to law", or "unconstitutional"). Although we do not have a contemporary account of the reasons for the creation of the grapheparanomon procedure, it is clear that this institution was intended an structured as a precaution against rash decision-making by the popular Assembly, particularly imprudent actions taken under the influence of demagogues", en: Lanni, Adriaan; Vermeule, Adrian, Precautionary Constitutionalism in Ancient Athens, en Cardozo Law Review, 12 (2013) 34, p. 901.

${ }^{11}$ Hansen, Mogens Herman, The sovereignty of the People's Court in Athens in the fourth century B.C. and the public action against unconstitutional proposals (Odense, Odense Universitetsforlag, 1974), p. 205. 
para fines políticos era el ostracismo, pero en el siglo IV de dicho período, fue el juicio ante la Asamblea, y en especial la graphéparanomon ${ }^{12}$.

\section{Procedimiento}

El graphéparanomon, en cuanto acusación de que una propuesta legislativa es contraria a la ley vigente, fue una de las protecciones constitucionales centrales del gobierno ateniense. Cualquier ciudadano podía solicitar la inconstitucionalidad de un decreto como paranomos, palabra que designaba un acto como contrario a la ley o inconstitucional ${ }^{13}$.

Por lo demás, tal acción de control de la legislación no podía ser promovida de oficio, sino que dependía de la solicitud de un ciudadano. Esto porque la solicitud debía ser introducida mediante una hypomosia, o sea, una alegación bajo juramento particular de que determinada norma era inconstitucional (paranomon). La acusación era escuchada por la Dikasteria ${ }^{14}$.

El juramento podía ser tomado antes de la votación, durante el debate en la Asamblea, o después de la votación. En el primer caso, el debate era suspendido y en el último caso, era suspendida la eficacia del decreto hasta que la Dikasteria emitiera un veredicto sobre la materia ${ }^{15}$. El ciudadano que había jurado la hypomosia aparecía ante el tribunal como acusador del individuo que había propuesto el decreto ${ }^{16}$. Una vez prestado el juramento, este estaba obligado a proseguir su acusación y a entregar para los thesmothetai una alegación escrita conteniendo todos los argumentos destinados a sustentar la inconstitucionalidad del decreto. En caso contrario, sería responsabilizado de abandono de una persecución pública, bajo multa de 1000 dracmas y la prohibición de presentar nuevamente una graphéparanomon ${ }^{17}$.

${ }^{12}$ Cfr. MacDowell, Douglas M., The law in classical Athens (New York, Cornell University Press, 1986), p. 50; Cf. Hansen, Mogens Herman, Nomos and Psephisma in Fourth-Century Athens, en Greek, Roman and Byzantine Studies, 19 (1978) 4, p. 317.

${ }_{13}$ Reduzzi Merola, Francesca, Il giudizio di costituzionalità nell'esperienza greco-romana, en Annali del Seminario Giuridico dell'Università di Palermo, 52 (2008), p. 45; Cfr. Manin, Bernard, Deliberación y discusión, en Revista Saap, 2 (2005) 2, pp. 248 ss.

14 "For a proposal which, though passed by the Ekklesia (or the Boule), contravened existing law or which had been passed by an irregular Procedure could be blocked by lodging an indictment for an ilegal proposal (graphéparanomón). This indictment could be brought by any citizen against the proposal itself at any time, but cleary if it was to achieve anything in that regard it was normally lodge more less immediately. The charge was head by de Dikasteria", en SincLaIR, R.K., Democracy and participation in Athens (New York, Cambridge University Press, 1933), p. 68.

${ }_{15}$ Lipsius, J.H., Das attischeRecht und Rechtsverfahren (Leipzig, O.R. Reisland, 1905), pp. 393-396.

16 "Whether a new proposal was for a law or for a decree, the proposer himself had a responsibility to make sure that it did not contravenue any existing law, either in form or in content. If it did, he could be prosecuted. As soon as the prosecutor made a sworn stantement (hypomosia) that he intended to bring a grapheparanomon ('prosecution for illegalities'), the proposed law or decree, whether the Ekklesia had already vote don it or not, was suspended until the trial had been held. If the defendant was found guilty, he was punished, usually by a fine, and his law or decree was annulled. If a man was convited three times of this type of offence, he suffered disfranchisement (atimia) in addition", en MacDowell, Douglas M., cit. (n. 12), p. 50.

${ }^{17}$ Harrison, A.R.W., The law of Athens: procedure (Londres, Oxford University Press, 
Así, la acusación debía consistir en la atribución de inconstitucionalidad de un decreto normativo, sea de una perspectiva formal o material, o que el contenido de la norma impugnada por esta vía, era perjudicial o indeseable a los intereses del pueblo. De este modo, un decreto podría ser considerado inconstitucional, por ejemplo, si fuera propuesto por un ciudadano que estuviera bajo la circunstancia de atimia, o sea, de privación total o parcial de los derechos cívicos de los ciudadanos atenienses ${ }^{18}$.

En el curso del siglo IV a. C., la noción de inconstitucionalidad se extendió también a la violación de los principios democráticos subyacentes a las leyes y además, a la mera acusación de incompatibilidad con los intereses del pueblo. De esta forma, en algunos discursos de sustentación del graphéparanomon, la acusación no se reducía sólo a la inconstitucionalidad de la norma impugnada, sino también sobre el perjuicio a los intereses del pueblo, tales como la concesión de honores y privilegios a una persona indigna de tales derechos; acción, que por su parte, era tramitada conforme al proceso de cualquier otra prosecución pública y funcionaba con a lo menos 501 jurados.

La decisión favorable sobre una acción de graphéparanomon tenía una doble consecuencia: por un lado el decreto impugnado era declarado nulo y sin efecto, y el ciudadano que lo propuso punido, muchas veces una punición simbólica, pero otras bajo la consecuencia de la atimia. Pero un tercer juicio en contra de una misma persona resultaba automáticamente en su total y permanente atimia. Por otro lado, la responsabilidad de los proponentes era limitada para un año, para posteriormente decantar en la sola consecuencia de anulación del decreto, no generando ningún efecto sobre el proponente.

\section{El significado de la 'graphéparanomon' en la política ateniense}

Interesante es destacar que, en principio, esta configuración procesal permitió que cualquier ciudadano actuase como una fuerza neutralizadora de la Asamblea, sometiéndola a las limitaciones de la ley. Sin embargo, en la práctica, una vez convocada la Asamblea para examinar la cuestión, la primera recomendación u orden era determinar su rechazo, pues la Asamblea votaba para alejar cualquier desafío legal que pudiera ir en contra de los intereses de la camarilla oligárquica que la controlaba, de modo que el examen de constitucionalidad en Atenas fue, de cierto modo, constantemente sofocado y así, la Asamblea se tornó en un consejo dominado por ciudadanos ricos, con sus intereses protegidos ${ }^{19}$. Esto confirma lo aseverado por Adrian Vermeule y Adriaan Lanni cuando explican que la graphêparanomôn era una institución de protección constitucional, pero no era, según los referidos autores, la forma preferida de elaboración de las leyes, toda vez que socavaba la autoridad de la Asamblea popular, sino que era considerada

1971), p. 12 ss.; Cfr. Hansen, Mogens Herman, cit. (n. 11), p. 206.

${ }^{18}$ Hansen, Mogens Herman, cit. (n. 12), pp. 315 ss.

${ }^{19}$ Frankel Paul, Ellen; Miller JR., Fred D.; Paul, Jeffrey; cit. (n. 1), p. 32; Cfr. Vermeule, Adrian; LaNNI, Adriaan, cit. (n.10), p. 21. 
una protección esencial contra los peligros de los demagogos y de los excesos de la democracia popular ${ }^{20}$.

De este modo, se puede decir que la graphéparanomon en estricto rigor corresponde a un procedimiento por el cual el Tribunal Popular o Dikasteria podía revertir las decisiones de la Asamblea, pero según Hansen, no se dirigía directamente en contra del pueblo, sino de los oradores que engañaban a la Asamblea con sus discursos ${ }^{21}$.Además, el voto en la Asamblea, se verificaba mediante el alzamiento de manos, mientras que en el Tribunal Popular, la votación era por medio de papeletas. En consecuencia, en la Asamblea el voto estaba condicionado a la posibilidad de presión de los diversos grupos, y por otro lado, en el Tribunal Popular, el método de voto protegía al ciudadano individualmente y limitaba las chances de corrupción ${ }^{22}$.

Sin embargo, la graphêparanomôn representaba una paradoja jurídica en el mundo ateniense: la ley no era una guía determinante para los veredictos del Tribunal Popular ateniense y, generalmente, estaba permitido a los jurados ignorarla en los casos individuales. Si la ley no tenía autoridad, ni era imprescindible para la decisión de los casos concretos, ni había la idea de la supremacía de la Constitución, ¿por qué los atenienses necesitaban de un procedimiento específico para proteger y alejar las normas contradictorias?

La primera suposición que nos podría indicar una respuesta a esta pregunta, es que los atenienses tenían una especial preocupación en el resguardo del sistema de producción democrático de las leyes y de toma de decisiones, pues en la práctica, solamente las normas que trataban acerca de procedimientos democráticos eran consideradas paranomôn (inconstitucionales), siendo de este modo, protecciones esenciales a la democracia ateniense ${ }^{23}$.

Para Bernard Manin, "la justificación del procedimiento contradictorio no podría ser valor de equidad y de imparcialidad sobre el cual fundamos frecuentemente de manera intuitiva. Es necesario suponer que al requerir el procedimiento contradictorio allí donde no había una víctima y su agresor alegado, los atenienses se basaban en otro valor de este procedimiento: su capacidad de hacer emerger la decisión más correcta y buena, o al menos su mejor aproximación”24.

Así, lo que podemos denominar como control de constitucionalidad en este período, estaba relacionado, no con la garantía de la superioridad formal y material del texto constitucional, sino más bien con la defensa de los procedimientos democráticos existentes hasta entonces ${ }^{25}$.

${ }^{20}$ Vermeule, Adrian; LanNi, Adriaan, cit. (n. 10), p. 22.

${ }^{21}$ Hansen, Mogens Herman, The athenian democracy in the age of Demosthenes: structure, principles, and ideology (Norman, University of Oklahoma Press, 1999), p. 207.

${ }^{22}$ Hansen, Mogens Herman, cit. (n. 21), p. 210.

23 "No sigle reason can be given why the Athenians wanted to subject the decisions of their Assembly to a second acrutiny and pass the decision to the courts. The most important reason was, no doubt, the respect all Greek felt for the superior wisdom and experience of age and for the oath sworn by the jurors; but the actual pattern of debate and manner of voting also helped to augment respect for the courts", en HaNSEN, Mogens Herman, cit. (n. 21), p. 209.

${ }^{24}$ Manin, Bernard, cit. (n. 13), p. 250.

${ }^{25}$ LANNI, Adriaan, cit. (n. 10), p. 6. 


\section{Organo competente}

La Dikasteria era un órgano fundamental para la mantención de la democracia, y con las reformas de Efialtes, fue revestida de nuevas funciones, tales como el control de las leyes, por haber sido establecida como un tribunal de primera jurisdicción, siendo responsable por juzgar la mayoría de los casos de orden privado (dikê) y de orden público (graphé). Para los juicios privados, la composición mínima de jurados era de 201 miembros, aunque podía ser aumentado a 401, si el valor de la causa superara una suma mayor de 1000 dracmas $^{26}$.

Por otro lado, en los juicios de naturaleza pública (graphé), el número de jurados ascendía a 501 miembros. Los jurados eran elegidos por medio de sorteo entre un grupo de 600 individuos, que eran pertenecientes a cada una de las diez tribus de Atenas, habiendo el número de 6000 potenciales miembros de un jurado disponibles, en total. Para los juicios públicos importantes, este número podría ser aumentado, llegando a los 6000 . Una curiosidad sobre la duración del juicio, era referente a la regla que un juicio no podría durar más de un día, siendo que algunas sentencias implicaban en una sanción inmediata ${ }^{27}$.

Los nomothetai eran uno de los tribunales de la Heliea, y que por medio de la graphéparanomon permitía a cualquier ciudadano hacer examinar toda ley que hubiera sido votada por la Asamblea o en curso de proposición. Si dicho tribunal decidía que la ley o la proposición de ley era contraria a las leyes generales de la polis, no solamente era anulada, sino que su autor estaba sujeto a sanciones graves, llegando como mencionamos anteriormente hasta a la atimia. Si el tribunal entendiera que la ley o la proposición de ley era compatible con la Constitución, esta era considerada aprobada sin reexamen por la Asamblea. La acción de graphéparanomon ofrecía al Tribunal Popular un rol mayor de que mero consejero constitucional. Con esto, la Heliea se convirtió con el transcurso del tiempo en un colegislador, compartiendo funciones legislativas con la Boulé y con la Asamblea o Ekklesía. Efectivamente, la aprobación de una propuesta de decreto por el Tribunal Popular generaba efectos de aprobación legislativa ${ }^{28}$.

A partir de 403/2 a.C. los atenienses introdujeron una distinción entre leyes (nomoi) y decretos (psephismata). En el siglo V, un acto normativo podría ser denominado como nomos, cuando se refería a una norma general aplicable por un período indefinido, mientras que la psephisma se trataba de un acto normativo con un objetivo específico y aplicable por un período limitado. En el siglo IV, el psephismata era revisado por la Asamblea y en el Consejo (Boulé), como también en el siglo $\mathrm{V}$, mientras que los nomois eran controlados por un especial cuerpo de legisladores denominados nomotheta $i^{29}$.

${ }^{26}$ BuCKeLEY, Terry, Aspects of Greek History: a source-based approach (New York, Routledge, 1996), p. 200.

${ }^{27}$ Cfr. Harrison, A.R.W., cit. (n.17), p. 47.

28 "This process was effectively an additional means of scrutiny, whereby any individual (ho boulomenos) could repeal a law either before oreven after its enactment by the nomothetai", en Kremmydas, Christos, Commentary on Demosthenes against Leptines (New York, Oxford University Press, 2012), p. 46.

${ }^{29}$ Hansen, Mogens Herman, Nomos ep' andri in Fourth-Century Athens: On The Law Qoted 
Primeramente, la graphéparanomon era utilizada tanto para decretos como para las leyes, pero después de 403/2 la graphéparanomon solamente podría ser utilizada en contra de decretos. Una nueva acción surgió para el control de las leyes y era denominada graphé nomon me epitedeionthenai ${ }^{30}$. El procedimiento era el mismo que el de la graphéparanomon y las consecuencias eran las mismas. La principal diferencia, no obstante, era que los jurados del Tribunal Popular decidían sobre los decretos y los nomothetai sobre las leyes ${ }^{31}$.

Los nomothetai era una institución que tenía por objetivo retirar de la Asamblea parte de su atribución en el proceso de cambio legislativo y del control de las leyes. Para aprobar una ley nueva, la Asamblea debía primero aprobar la iniciativa, presentada por un magistrado o por un simple ciudadano, decidir el número de nomothetai que habrían de decidir la propuesta legislativa, y designar a cinco defensores de la ley antigua, pues toda innovación se presentaba como un cambio legislativo, de modo que debiera adaptarse al procedimiento contradictorio o deliberativo. Los nomothetai eran electos, posiblemente por sorteo, entre quienes hubieran prestado este año juramento heliástico y constituían un jurado de diferente tamaño, según la importancia de la propuesta de ley. Después de escuchar al proponente de la nueva ley y a los defensores de la antigua, los nomothetai decidían en el día y recibían su correspondiente remuneración, como los jueces ordinarios.

La función del nomotheta no se asemejaba a la figura del legislador propiamente tal, tampoco a de una comisión de técnicos legislativos. El objetivo era establecer una tramitación más compleja y deliberativa de los procesos de modificación y de revisión de las leyes (nomos).

\section{Demóstenes: el discurso “COntra Timócrates”}

Muchas de las evidencias sobre el proceso de graphêparanomôn pueden ser encontradas en los discursos de Demóstenes, particularmente en aquel denominado Contra Timócrates.

En este discurso, la causa de la acusación, presentada por Diodoro y Euctemón, se fundó en los siguientes hechos: en el año 355 a.C., un trirreme ateniense responsable por el transporte de tres embajadores desde Atenas hasta Caria, entre los que se encontraba Androción, capturó un barco mercante egipcio que pertenecía a comerciantes de Náucratis ${ }^{32}$. Éstos exigieron a Atenas la restitución del cargamento apresado, pero el pueblo decidió que esos bienes, por pertenecer a enemigos, eran susceptibles de ser confiscados a favor de Atenas en virtud de las leyes de guerra, toda vez que, siendo un barco egipcio y estando Egipto en guerra con Persia, a la sazón amigo de Atenas, no había lugar a la reclamación de

at Andocides 1.87, en Greek, Roman and Byzantine Studies, 57 (2017) 2, p. 268. Cfr. HaNSEN, Mogens Herman, cit. (n. 12), pp. 315 ss; TodD, S. C., The shape of Athenian law (New York, Oxford University Press, 1993), p. 57.

${ }^{30}$ Lipsius, J.H., Das attischeRecht und Rechtsverfahren (Leipzig, O.R. Reisland, 1905), p. 387.

31 En Hansen, Mogens Herman, cit. (n. 21), p. 212.

32 Cfr. Pavón Torrejón, Pilar, La cárcel y el encarcelamiento en el mundo romano (Madrid, CSIC, 2003), p. 52. 
lo que a todas luces era una propiedad del enemigo. Sin embargo, los trierarcos, Arquebio y Lisitides, en vez de entregar al erario los nueve talentos y treinta minas a que ascendía la suma resultante de la venta de lo aprehendido, se los confiaron a los embajadores -Androción, Gláucetes y Melanopo- quienes retuvieron dicha cantidad de dinero ${ }^{33}$.

Cuando el tema ya parecía haberse olvidado, Aristofonte, en un momento de dificultad financiera de Atenas, hizo aprobar un decreto, en virtud del cual, todos aquellos ciudadanos que supiesen de individuos que mantuvieran dinero del Estado retenido, eran exhortados a denunciarlos sin más. Fue ahí cuanto Euctemón presentó una denuncia en contra de los trierarcos por su incorrecto proceder ${ }^{34}$.

La cantidad adeudada por los embajadores, ascendía en principio, a nueve talentos y treinta minas, como anteriormente se mencionó. Pero dado según la ley, todo deudor del Estado que dejase pasar el plazo legal establecido para el pago de su deuda debía pagar el doble de la suma adeudada no reintegrada en el momento estipulado y, además, por otro lado, una parte del botín apresado al barco mercante egipcio, correspondía por derecho a los dioses - esto es, el diezmo a Atenea, y una cincuentava a los demás dioses- y quien demorase en saldar las deudas religiosas estaba obligado a pagar la cantidad resultante de multiplicar por diez dicho monto. Así, los malhadados embajadores habían de hacer frente a una deuda que era equivalente a la suma inicial pero multiplicada por tres ${ }^{35}$.

De este modo, como es fácil entender, los denunciados trataron de escapar a tal castigo, para lo cual atacaron el decreto de Euctemón acusándolo de inconstitucional. Por otro lado, con el fin de que la denuncia en su contra no obtuviera éxito ${ }^{36}$, Androción y sus colegas recurrieron a Timócrates, quien propuso la dictación de una ley fraguada exclusivamente para socorrer a sus inculpados amigos $y$, mediante astutas estratagemas y un reprochable proceder, consiguió que fuera votada por una asamblea extraordinaria de nomotethai, convocada a toda prisa para proveer urgentemente a los gastos de las inminentes fiestas de las Panateneas ${ }^{37}$.

En el discurso de Demóstenes Contra Timócrates se explica que aquél había realizado una propuesta de ley en la que se estipulaba que los deudores del Estado que hubieran sido castigados a una pena accesoria de encarcelamiento por una ley ya existente o por las que en el futuro se votaran, debían ser liberados de la pena accesoria de encarcelamiento hasta la novena pritanía ${ }^{38}$ del año si presentaban

33 Demóstenes, Discursos politicos (trad. Antonio López Eire, Madrid, Gredos, 1985), p. 113; Cfr. Canevaro, Mirko, Nomothesia in classical Athens: what sources should we believe?, en The classical quarterly, 63 (2013) 1, pp. 144 y ss.

34 Demóstenes, cit. (n. 33), p. 125.

35 Cfr. Pavón Torrejón, Pilar, cit. (n. 32), pp. 52 ss.

${ }^{36}$ Conforme se puede denotar del discurso Contra Androción. Cfr. Demóstenes, cit. (n. 33), pp. 379 ss.

37 Demóstenes, cit. (n. 33), p. 115.

38 Una pritanía era un lapso de tiempo de treinta y cinco o treinta y seis días, resultantes de dividir en diez secciones el año; en tantas partes, por tanto, como tribus había en Atenas, a cada una de las cuales les correspondía tener miembros senadores de la Boulé ejerciendo el poder ejecutivo durante el correspondiente período, denominado por esta razón "pritanía”. Cfr. Aristóteles, Constitución de los atenienses (Madrid, Abada, 2005). 
avales que se hicieran cargo de la multa impuesta al deudor. Si estos no pagaban, debían ser encarcelados y sus bienes confiscados ${ }^{39}$.

La ley propuesta por Timócrates presentaba defectos de fondo y de forma. En efecto, uno de los argumentos de Demóstenes se centraba en la ilegalidad de proponer una ley con efectos retroactivos, como quedaba claramente expresado en la propuesta de Timócrates ${ }^{40}$. Además, pretendía evitar la condena estipulada para los deudores del Estado, hecho que iba claramente contra la ley, pues los recaudadores de impuestos debían inscribir en tablillas a los deudores públicos, de tal manera que se pudieran proceder contra ellos, y a la vez, éstos tenían la posibilidad de pagar el doble de la cantidad debida o ser encarcelados ${ }^{41}$.

En los hechos, lo que intentaba Timócrates, era que esta pena suplementaria de cárcel fuera evitada mediante la presentación de avales, obligando así O sea, ante ello, el Estado debía retrasar el cobro de la multa, y no tomar la medida de garantía que era el encarcelamiento accesorio. Aparentemente, el juramento del Consejo libraba del encarcelamiento a los deudores del Estado, puesto que no eran aludidos. No obstante, como señalaba Demóstenes, el juramento no era una ley. Además, la limitación se hacía respecto el encarcelamiento previo al juicio y no sobre el encarcelamiento que emanaba de una sentencia ${ }^{42}$.

La aprobación de la propuesta timocrática podía traer consecuencias muy graves, pues si se eliminaba la imposición de la pena suplementaria al encarcelamiento para los deudores del Estado, debía extenderse también a las otras sentencias que implicaban la misma pena. A ello se añadía que la propuesta se presentaba con efectos retroactivos y por lo tanto, todos los autores de este delito que estaban en la cárcel deberían ser liberados. Por otro lado, detrás de la polémica sobre la supresión de la pena subyace un problema de fondo. El dinero recaudado se utilizaba para el pago de las reuniones de la Asamblea, de los servicios religiosos, de la Boulé, del ejército, etc. La ley obligaba al deudor a pagar con el recurso de la pena suplementaria de cárcel y, además, se obtenía el beneficio de la imposición de la multa. Por otra parte, las arcas de la polis se veían beneficiadas con los ingresos procedentes de las penas pecuniarias que se imponían bajo la fuerza de la ley ${ }^{43}$.

Así, el descenso de la cuantía del tesoro público producía un gran detrimento para el bienestar común. De ahí se desprende que, si se eliminaba este recurso legal para obligar al pago de la deuda, este hecho afectaba, en definitiva, el mantenimiento de la propia ciudad. Uno de los últimos argumentos utilizados por Demóstenes radicaba en que las leyes eran elementos principales que habían dado

39 Pavón Torrejón, Pilar, cit. (n. 32), p. 52.

${ }^{40}$ En verdad, Timócrates tenía la intención de beneficiar a tres amigos suyos con tal propuesta. Éstos eran: Androción, quien había sido atacado por Demóstenes en un discurso escrito en el año 355 a. C., Glaucetes y Melánopos. Los tres habían sido acusados de un delito contra el Estado. Mientras navegaban hacia Caria en visita diplomática, su nave apresó a un mercante Egipcio de Naucratis. Los tres embajadores decidieron no entregar la mercancía al estado ateniense, a pesar de que ello suponía el delito de retener propiedad pública. Cfr. PAvÓN Torrejón, Pilar, cit. (n. 32), p. 52.

41 Demóstenes, cit. (n. 33), p. 127; Cfr. Pavón Torrejón, Pilar, cit. (n. 32), p. 52.

42 Pavón Torrejón, Pilar, cit. (n. 32), p. 54; Lanni, Adriaan, cit. (n. 10), pp. 10 ss.

43 Pavón Torrejón, Pilar, cit. (n. 32), p. 54. 
a Atenas sus riquezas y prosperidad, de manera que todo ello se arruinaría si se admitiera una ley que propugnaba la impunidad de los crímenes.

Consecuentemente, no es de extrañar que Euctemón y Diodoro planteasen contra aquella ley un recurso por ilegalidad como el anteriormente mencionado graphêparanomôn. La vista de la causa tuvo lugar en el año 353 o 352 a. C., fecha justamente en la que Diodoro, quien en esta ocasión hizo uso de la palabra primero, empleó el discurso que había confeccionado Demóstenes, señalando que esta vez ya no era mera deuterología -que consistía en la réplica delante de los tribunales atenienses-, sino que fundamentaba un discurso acusatorio de inconstitucionalidad específico ${ }^{44}$.

Del referido discurso podemos llegar a la conclusión que el sistema de control de las leyes en Atenas era muy complejo y, a la vez, muy similar al control de constitucionalidad que tenemos hoy. El procedimiento de producción y control de las leyes en Atenas, conocido como nomothesia, se iniciaba en la Asamblea con la votación acerca si se era posible aceptar la nueva propuesta de ley ${ }^{45}$. Nuevas leyes podían ser propuestas en cualquier época del año. Una vez presentada la propuesta, la ley en elaboración tenía que ser publicada frente a los Héroes Epónimos y leída en muchas oportunidades en la Asamblea para que el pueblo, tomando conocimiento del contenido de la nueva ley, pudiera votar. Antes de la promulgación de la nueva ley, las contrarias vigentes deberían ser derogadas ${ }^{46}$. Asimismo, en la tercera reunión de la Asamblea, después de la votación preliminar, el pueblo emitía un decreto de nombramiento para el nomothetai y además elegía a sunêgoroi para defender la mantención de las leyes contrarias a la nueva ley propuesta. Si alguna de estas reglas fuera ignorada, cualquier ciudadano podía presentar una acción pública (graphê 'nomon mêepitêdeionthenai') para impedir la entrada en vigencia de una ley defectuosa ${ }^{47}$.

\section{PRINCIPIOS DE DERECHO PROCESAL CONSTITUCIONAL EN \\ LA ÉPOCA CLÁSICA ATENIENSE}

Así, del discurso en Contra Timócrates, podemos extraer algunos principios y debates constitucionales procesales que aún persisten en el mundo actual. Pasamos abajo a sistematizarlos.

\section{El principio del debido proceso legislativo}

La primera acusación que hace Demóstenes es que la propuesta y aprobación de la ley de Timócrates no observó las normas vigentes y los procedimientos

${ }^{44}$ Demóstenes, Discursos políticos, cit. (n. 33), p. 115; López Eire, Antonio, Demóstenes: estado de la cuestión, en Estudios Clásicos, Consejo Superior de Investigaciones Científicas, 20 (1976) 78, pp. 207 ss.

45 VAZ DE Lima Filho, Acácio, O poder na antiguidade: aspectos históricos e jurídicos (São Paulo, Saraiva, 1999), p. 98.

${ }^{46}$ MacDowell, Douglas M., The law in classical Athens (New York, Cornell University Press, 1986), pp. 50 ss.

47 Canevaro, Mirko, cit. (n. 33), p. 158; Cfr. Hansen, Mogens Herman, cit. (n. 15), p. 205. 
necesarios para la formación de una nueva ley, lo que demuestra la presencia de una noción del principio del debido proceso legislativo ${ }^{48}$. Pues conforme asevera Demóstenes "están, varones atenienses, definidos con exactitud y claridad en las leyes que son vigentes para nosotros todos los requisitos que hay que cumplir respecto de las leyes que van a ser propuestas. Y en primer lugar, antes de nada, queda prescrito el momento en que es apropiado legislar; luego, ni siquiera en esa ocasión el legislador ha concedido que ejerza esta función todo aquel a quien le parezca bien; por el contrario, ordena que primeramente se redacte el texto y se exponga ante las estatuas de los Héroes epónimos para que lo examine todo el que quiera; luego, manda que la misma ley se promulgue para ser aplicada a todos, $y$, además, que se deroguen las leyes contrarias, y dicta otras órdenes acerca de las cuales tal vez ahora no es urgente que vosotros escuchéis exposición ninguna. Pero si alguien infringe una de esa normas, se da poder, a quien lo desee, para presentar una acusación por escrito. Pues bien, si Timócrates no estuviera sujeto a todas estas prescripciones y no hubiera propuesto la ley en contra todos esos reglamentos, podría uno acusarle de un solo cargo, cualquiera que éste fuera" ${ }^{\text {"ł9 }}$. En contra de la inobservancia del debido proceso legislativo, se podía presentar la acción de graphêparanomôn, por la inconstitucionalidad formal de la ley ${ }^{50}$. Es interesante notar, como ya se señaló, que los atenienses contaban con un sistema complejo para la aprobación de las leyes y de gran participación entre sus ciudadanos ${ }^{51}$. En efecto, la presentación de la propuesta de la ley frente a la Asamblea y la oportunidad para su impugnación era algo fundamental para su aprobación. La idea de que la ley debía ser formalmente adecuada estaba estructurada de manera muy rigurosa, siendo posible afirmar que la validez de las leyes en Grecia también dependía de su aspecto formal ${ }^{52}$.

De hecho, según Adriaan Lanni, los procedimientos de revisión de la ley en Atenas estaban mucho más enfocados a la salvaguardia de la toma de decisión popular en la Asamblea y en los tribunales que de cumplir con la consistencia sustantiva de la ley. Bajo este punto de vista, los argumentos relacionados a las irregularidades formales o de procedimiento por el que pasa una ley en Atenas, reflejan la preocupación de los atenienses en la protección del proceso legislativo. De la simple lectura de los discursos de Demóstenes, se puede advertir, que la mayoría de las alegaciones basadas en alguna contradicción directa con la ley o en una contravención de los principios generales del derecho ático, implicaban la contradicción con derechos procesales básicos o que de algún modo comprometían la integridad del proceso de resolución judicial en los tribunales populares. De este modo, la graphêparanomôn y también la graphê nomon me epitedeiontheinai

48 Vaz de Lima Filho, Acácio, cit. (n. 45), pp. 98-99.

49 Demóstenes, cit. (n. 33), pp. 128-129.

50 Sellers, Mortimer; TOMASZEWSKI, Tadeusz; The rule of law in comparative perspective (Baltimore, Springer, 2010), p. 12.

${ }^{51}$ Canevaro, Mirko, cit. (n. 33), p. 144; Harris, Edward M., The rule of law in action in democratic Athens (New York, Oxford University Press, 2013), p. 244.

${ }_{52}$ Yunis, Harvey, Law, politics and the graphéparanomon, en Greek, Roman and Byzantine Studies, 29 (1988) 4, pp. 361-382. 
eran consideradas vitales para la preservación de la democracia ateniense ${ }^{53}$, siendo así, la decisión de los nomotethai era inmutable, con el objetivo de proteger el debido proceso democrático.

\section{Los 'nomotethai' como guardianes de la ley}

Los nomotethai eran un grupo de ciudadanos seleccionados para juzgar la constitucionalidad formal y material de las leyes en Atenas ${ }^{54}$. Ellos tenían el status de guardianes de las leyes, así como los Tribunales Constitucionales la tienen en relación a la Constitución, atribución conferida en referencia a la discusión entre Hans Kelsen y Carl Schmitt de guardianes de la Constitución ${ }^{55}$; en efecto, se denota de las palabras de Demóstenes en el discurso en contra de Timócrates que: “[...] el legislador dictó las prescripciones ésas, y además, porque quería estableceros como guardianes de las leyes, pues sabía bien esto otro: que las demás salvaguardas que él habia establecido por escrito son fáciles de burlar de muchas maneras [...]" 56 . De este modo, la función de este grupo de ciudadanos, era velar para que las nuevas leyes tuvieran coherencia con las demás leyes vigentes, preservando así, la estabilidad del ordenamiento jurídico ateniense ${ }^{57}$.

\section{La necesidad del control de las leyes en virtud de la coherencia del sistema jurídico}

El sistema jurídico ateniense tenía normas específicas para evitar las antinomias. Demóstenes, en su discurso Contra Leptine, afirma que "[...] el procedimiento por el que Solón ordena se establezcan las leyes (y qué espléndido es), primeramente, ante vosotros, los jurados, ante quienes justamente también tienen lugar las demás ratificaciones; luego, anulando las leyes contradictorias, con el fin de que haya una sola ley acerca de cada una de las cuestiones y ese mismo hecho no inquiete a los particulares $y$ les haga estar en inferioridad de condiciones con respecto a quienes conocen la totalidad de la legislación, antes bien, puedan todos leer los mismos textos y entender las disposiciones de derecho expresadas en forma sencilla y clara" 58 . Para los atenienses, no era lícita la derogación de una ley, a no ser ante los nomotethai. Y en este caso, cualquier ciudadano podía presentar otra ley en sustitución de la que se pretendía derogar. De esta propuesta se realizaba una votación a mano alzada, primeramente referida a la ley vigente, en el sentido de si al pueblo le parece o no apropiada, y, posteriormente, acerca de la propuesta de nueva ley, para que finalmente, sólo

53 LANNI, Adriaan, cit. (n. 10), pp. 6 y 8.

54 Palao Herrero, Juan, El sistema jurídico ático clásico (Madrid, Dykinson, 2007), p. 164.

55 "Pues bien, tratando de protegeros de tal suceso, el legislador dictó las prescripciones ésas, y además, porque quería estableceros como guardianes de las leyes”, en DEMÓsTENES, cit. (n. 33), p. 137; Cfr. Kelsen, Hans, Jurisdição constitucional (São Paulo, Martins Fontes, 2003); SCHMITT, Carl, O guardião da constituição (Belo Horizonte, Del Rey, 2007); GLOTZ, Gustave, A cidade grega (Rio de Janeiro, Bertrand Brasil, 1988), p. 136; VAZ DE Lima FilHo, Acácio, O controle de constitucionalidade: bosquejo de sua história, em Revista da Faculdade de Direito, 95 (2000), pp. 293-323; Vaz de Lima Filho, Acácio, cit. (n. 45), pp. 98-99.

56 Demóstenes, cit. (n. 33), p. 137.

57 MacDowell, Douglas M., cit. (n. 12), p. 44.

58 Demóstenes, cit. (n. 33), p. 219. 
una de ellas resultase válida. La nueva ley no podía de manera alguna contradecir las demás leyes vigentes ${ }^{59}$.

Metodológicamente, es importante destacar que, no obstante esta preocupación de los atenienses de evitar contradicción entre normas jurídicas, lo cierto es que no se puede afirmar la existencia de un ordenamiento jurídico griego en el sentido moderno, incluso algunos autores entienden que la expresión derecho griego no tiene ninguna utilidad analítica ${ }^{60}$. Por otro lado, Foxhall y Lewis no rechazan la noción de derecho griego como categoría de investigación útil, sino que aceptan su importancia observando una coherencia estructural de comportamiento legal que sugiere una noción de derecho griego ${ }^{61}$, como el caso del modelo islámico de sistemas independientes ${ }^{62}$.

\section{El proceso constitucional como proceso dialéctico: la deliberación como garantía de decisiones correctas}

Las decisiones de la Asamblea podían someterse a una segunda lectura ante el pueblo ateniense. El hecho que se impusiera una autoridad superior en esta segunda lectura llama particularmente la atención, pues ante los tribunales, la decisión era examinada necesariamente de manera contradictoria, otorgando a cada una de las partes el tiempo para preparar sus alegatos.

El caso de la graphêparanomôn es evidentemente más complejo, pues la estructuración del examen de constitucionalidad de manera bilateral, esto es, según dos polos opuestos, uno atacando la decisión y otro defendiéndola, era una construcción institucional deliberadamente impuesta. La justificación del procedimiento en este caso, no tiene relación con la idea de que el contradictorio garantiza la equidad y la imparcialidad del juicio, sino que se justificaba en la búsqueda de decisiones correctas y buenas.

Para Bernard Manin, "los atenienses esperaban que del segundo examen de ciertas decisiones de la Asamblea por los tribunales fuera más razonado y que estuviera en mejores condiciones de discernir los verdaderos intereses de la polis,

59 Demóstenes, cit. (n. 33), p. 132; Lanni, Adriaan, cit. (n. 10), pp. 147 ss; Petrie, Alexander, Introducción al estudio de Grecia (México, Fondo de Cultura Económica, 1995), p. 92; Cfr. Hansen, Mogens Herman, cit. (n. 11), p. 205; Igualmente, Melissa Schwartzberg enseña que "the 'grapheparanomon' was a mechanism by which the proposer of a decree (psephisma) could be subject to public prosecution on the grounds that the decree was contrary to the laws in force, hostile to the interests of the people, or procedurally invalid. Because the 'grapheparanomon' served to ensure that a decree did not conflict with an existing law (nomos), it constituted a key mechanism by which the hierarchy of norms could be secured", en: SCHWARTZBERG, Melissa, Was the grapheparanomona form of judicial review?, conferencia publicada en Cardozo Law Review, 34 (2013), pp. 1049-1062.

${ }^{60}$ Todd, Stephen; Millet, Paul, Law, society and Athens, en Cartledge, Paul; Millett, Paul; TodD, Stephen, Nomos: Essays in Athenian law, politics and society (Cambridge, Cambridge University Press, 1990), pp. 8-9.

${ }^{61}$ FoxHALl, Lin; LeWIS, Andrew (edit.), Greek law in its political setting: justifications not justice (Oxford, Oxford University Press, 1996), pp. 2-3.

${ }^{62}$ Vaneciano, Gustavo, La discreción judicial en los jueces griegos arcaicos y el problema del precedente, en AmEs, Cecilia; SAGRISTANI, Marta (comp.), Estudios interdisciplinarios de historia antigua (Córdoba, Encuentro, 2007), I, p. 306. 
no que fuera más justo y equitativo" ${ }^{33}$. En este aspecto el valor del principio contradictorio se relaciona con la expectativa de corrección de la decisión, estimando que las decisiones con deliberación eran más justas y correctas.

\section{El valor de la sentencia en Atenas}

Las decisiones en Atenas eran extremamente rígidas, de hecho, se puede decir que en este período, prevalecía una noción estricta de la inmutabilidad absoluta de la sentencia. Cabe resaltar que, también en el discurso de Demóstenes en Contra Timócrates, se expresa la idea de que la decisión de los jurados nomothetai no podía revertir una sentencia judicial común, de lo que es posible deducir, que el órgano responsable por la revisión de constitucionalidad estaba impedido de controlar el contenido de las sentencias, pues las decisiones de este órgano no tenían efecto retroactivo ${ }^{64}$.

Por otro lado, en relación a la acción específica de control de constitucionalidad en la Grecia antigua, la acusación de inconstitucionalidad podía ser presentada por cualquier ciudadano, sea de ley ya vigente o de aquellas en trámite de aprobación. Si los jurados nomothetai decidían por la inconstitucionalidad, la ley era considerada invalida y su demandante condenado a una multa. Una interesante observación, que sirve para resumir lo anteriormente mencionado, la otorga Battaglini, quien afirma que en Atenas la sanción era en contra del proponente de la acción de control de constitucionalidad y no solamente en virtud de la norma atacada, pues había un onus para quien propuso la norma inconstitucional ${ }^{65}$ : el individuo que por tres ocasiones propusiera una ley considerada inconstitucional perdía la calidad de ciudadano, indicando la seriedad con que se trataba la constitucionalidad de las leyes en Atenas ${ }^{66}$.

Ahora, si los jurados nomothetai confirmasen la constitucionalidad de la ley en debate, la decisión ganaba el status de promulgación, incluso si la Asamblea no hubiese aún aprobado la ley. Para la concepción moderna, este procedimiento ofendería la separación de poderes, pues la Corte Constitucional ${ }^{67}$, en estas circunstancias, pasa a ser responsable por la promulgación de la legislación. Sin embargo, para los atenienses, esto no era un problema, pues la Corte Constitucional estaba concebida y era representada por aproximadamente 500 jurados, formados por ciudadanos del pueblo, legitimando así tal procedimiento. Asimismo, no había hasta entonces la noción exacta de la tripartición de los poderes según la concepción moderna ${ }^{68}$. El valor de la cosa juzgada constitucional en Atenas, en

63 Manin, Bernard, cit. (n. 13), p. 250.

${ }^{64}$ Demóstenes, cit. (n. 33), p. 154.

65 Battaglini, Mario, Contributi alla storia del controllo di costituzionalità delle leggi (Milano, Giuffrè, 1957), pp. 8-10; Cfr. CAPPELletTI, Mauro, Alcuni precedenti storici del controllo giudiziario di costituzionalità delle leggi, en Rivista di Diritto Processuale Civile, 21 (1966), p. 57.

${ }^{66}$ Cfr. Yunis, Harvey, cit. (n. 52), p. 366; Johnstone, Steven, Disputes and democracy: the consequences of litigation in Ancient Athens (Austin, University of Texas Press, 1999), p. 37.

${ }^{67}$ La comparación aquí realizada en sentido amplio del órgano de nomothetai con la concepción moderna de Corte Constitucional, no asumiendo que en Grecia había una Corte Constitucional, en sentido actual.

${ }^{68}$ Cfr. Montesquieu, El espiritu de las leyes (Madrid, Istmo, 2002). 
sentido amplio, era tan importante que se equiparaba a un acto propio del poder legislativo, teniendo fuerza de promulgación. De este modo, las decisiones en control de constitucionalidad pasaban a hacer parte de la Constitución, integrando la Constitución material y formal ateniense ${ }^{69}$.

Así, es posible afirmar, que la decisión constitucional en Atenas, asumía la cualidad de cosa juzgada en el sentido tradicional del término, tornándose inmutable, no siendo admisible recurso alguno que pueda reformar la decisión de los nomothetai. De este modo, se puede concluir que los atenienses con este sistema de protección y de estabilidad de sus normas, con efecto erga omnes, consiguieron establecer el trato igualitario entre los ciudadanos acerca de la aplicación de la ley, además de la permanencia y coherencia de su ordenamiento jurídico.

\section{CONCLUSIONeS}

Del análisis del control de constitucionalidad en Atenas podemos extraer las siguientes conclusiones:

1. Que la Constitución ateniense estaba fundada en una ética natural de sus ciudadanos, funcionando de acuerdo con ideales de justicia que dominaban la época clásica, siendo que la noción de Constitución era una noción ética, en la cual la justicia guiaba el uso y desarrollo de las leyes, no cumpliendo, de este modo, la Constitución el rol de ley fundamental del Estado.

2. El término Constitu ción se utilizaba en un sentido amplio, pues dicho concepto era entendido como una composición de instituciones políticas, las que incluían normas detalladas de aspectos religiosos, de derecho de familia, de derecho penal y económico. De lo cual, podemos notar que el concepto de Constitución no estaba solamente vinculado con la estructura política, sino que también estaba relacionado con derechos sustanciales de importancia para los individuos de esta sociedad.

3. Al final del siglo V a.C., un nuevo cuerpo conocido como nomothetai fue creado para ratificar las leyes. De este modo, habían dos procedimientos específicos para controlar la legislación: uno era el graphêparanomôn en contra de un psêphisma, o sea una acción pública en contra de un decreto ilegal, y también la graphê 'nomon mêepitêdeionthenai' en contra de nomos, o sea una acción pública en contra una ley escrita.

4. El graphêparanomôn, o sea, la acusación de que una propuesta legislativa es contraria a la ley vigente, fue una de las protecciones constitucionales centrales del gobierno ateniense. Cualquier ciudadano podría proponer la graphêparanomôn frente a la Asamblea, siendo que un cuerpo de jurados nomothetai debería analizar y aceptar la legalidad de la propuesta antes que la Asamblea pudiera votar la cuestión invocada. Esta legalidad de la propuesta era considerada de modo distinto de la cuestión sobre su aprobación, siendo que esta legalidad podría ser impugnada incluso después de la aprobación de la ley, revelando aquí, el control

69 Petrie, Alexander, Introducción al estudio de Grecia (México, Fondo de Cultura Económica, 1995), p. 92. 
de constitucionalidad preventivo y también reparador, constituyendo un sistema mixto en cuanto al momento de realizar el "control de constitucionalidad".

5. Los atenienses tenían una especial preocupación en el resguardo del sistema de producción democrático de las leyes y de toma de decisiones. El control de constitucionalidad en el período clásico estaba relacionado, no con la garantía de la superioridad formal y material del texto constitucional, sino más bien estaba para defender los procedimientos democráticos que existían hasta entonces.

6. Los procedimientos de revisión de la ley en Atenas estaban enfocados para la salvaguardia de la toma de decisión popular en la Asamblea y en los tribunales. Bajo este punto de vista, los argumentos con respecto a las irregularidades formales o de procedimiento en el que pasaba la ley en Atenas, reflejan las preocupaciones de los atenienses en proteger el proceso legislativo. De este modo, la graphêparanomôn y también la graphê nomon me epitedeiontheinai eran consideradas vitales para la preservación de la democracia ateniense, siendo así, la decisión de los nomotethai era inmutable, con el objetivo de proteger el debido proceso democrático.

7. De los discursos de Demóstenes se puede denotar que los nomotethai eran un grupo de ciudadanos seleccionados para juzgar la constitucionalidad formal y material de las leyes en Atenas. Ellos tenían el status de guardianes de las leyes, así como los Tribunales Constitucionales tienen la atribución conferida en referencia a la discusión entre Hans Kelsen y Carl Schmitt de guardianes de la Constitución.

8. El sistema jurídico ateniense tenía normas específicas para evitar las antinomias, sin embargo, metodológicamente, es importante destacar que, no obstante los atenienses tenían una preocupación acerca de la no contradicción entre normas jurídicas, cierto es que no se puede afirmar que existía un ordenamiento jurídico ateniense en el sentido moderno, siendo que la coherencia estructural de comportamiento legal que sugiere una noción de derecho griego se asemeja al modelo islámico de sistemas independientes.

9. Las decisiones en Atenas eran extremamente rígidas, pudiendo decirse que en este período prevalecía una noción estricta de la inmutabilidad absoluta de la sentencia. También, por los discursos de Demóstenes, se puede extraer que la decisión de los jurados nomothetai no podían revertir una sentencia judicial común, siendo que aparentemente, se puede deducir que el órgano responsable por la revisión de constitucionalidad estaba prohibido de controlar el contenido de las sentencias ordinarias, pues las decisiones de este órgano no tenían efecto retroactivo.

10. En relación a la acción específica de control de constitucionalidad en la Grecia antigua, la acusación de inconstitucionalidad podría ser presentada por cualquier ciudadano, sea de ley ya vigente o de aquellas en trámite de aprobación. Si los jurados nomothetai decidían por la inconstitucionalidad, y la ley era considerada invalida, su demandante era condenado a una multa. En Atenas, la sanción era en contra del proponente de la acción de control de constitucionalidad y no solamente en virtud de la norma atacada, pues había un onus para quien propuso la norma inconstitucional. El individuo que por tres ocasiones propusiera una ley considerada inconstitucional perdía la calidad de ciudadano, indicando la seriedad con que se trataba la constitucionalidad de las leyes en Atenas. 
11. De la confirmación de la constitucionalidad por parte de los jurados nomothetai, la decisión ganaba el status de promulgación, incluso si la Asamblea no hubiese aún aprobado la ley. Para la concepción moderna, este procedimiento ofendería la separación de poderes, pues la Corte Constitucional, en estas circunstancias, pasaría a ser responsable por la promulgación de la legislación. Sin embargo, para los atenienses, esto no era un real problema, pues primeramente no había la noción de tripartición de los poderes, y en segundo lugar, la Corte Constitucional (nomothetai) estaba concebida y era representada por quinientos jurados, formados por ciudadanos del pueblo, legitimando democráticamente así, tal procedimiento.

12. Por fin, el valor de la cosa juzgada constitucional en Atenas, era tan importante que se equiparaba a un acto propio del poder legislativo, teniendo fuerza de promulgación. De este modo, las decisiones en control de constitucionalidad pasaban a hacer parte de la Constitución, integrando la Constitución material y formal ateniense.

\section{BiBLIOGRAFÍA}

Ansieta Núñez, Alfonso, El concepto de tirano en Aristóteles y Machiavello, en Revista de Derecho Universidad Católica de Valparaiso, 11 (1987), pp. 79-88.

Aristóteles, Constitución de los Atenienses (Madrid, Abada, 2005).

Aristoteles, Política (2a edición, Madrid, Centro de Estudios Políticos y Constitucionales, 1997).

Battaglini, Mario, Contributi alla storia del controllo di costituzionalità delle leggi (Milano, Giuffrè, 1957).

BuCKeley, Terry, Aspects of Greek History: a source-based approach (New York, Routledge, 1996).

Canevaro, Mirko, Nomothesia in classical Athens: what sources should we believe? en The classical quarterly, 63 (2013) 1, pp. 139-160.

Cappelletti, Mauro, Alcuni precedenti storici del controlo giudiziario di costituzionalità delle leggi, en Rivista di Diritto Processuale Civile, 21 (1966) 1, pp. 52-69.

-- Dimensiones de la justicia en el mundo contemporáneo (México, Porrúa, 1993).

-- O controle judicial de constitucionalidade das leis no direito comparado, (2a edición, Porto Alegre, Fabris, 1984).

Demóstenes, Discursos politicos (trad. Antonio Lopez Eire, Madrid, Gredos, 1985).

Everson, Stephen, Aristotle: the politics and the constitution of Athens (Cambridge, Cambridge University Press, 1996).

FoXHALL, Lin; LeWIS, Andrew (edit.), Greek law in its political setting: justifications not justice (Oxford, Oxford University Press, 1996).

Frankel Paul, Ellen; Miller JR., Fred D.; Paul, Jeffrey; What should constitutions do? (Cambridge, Cambridge University Press, 2011).

Gagarin, Michael, Early greek law (Los Angeles, California Press, 1986).

Glotz, Gustave, A cidade grega (Rio de Janeiro, Bertrand Brasil, 1988).

GuZman Brito, Alejandro, El vocabulario histórico para la idea de constitución política, en Revista de Estudios Históricos-Jurídicos, 24 (2002), pp. 267-313.

Hansen, Mogens Herman, Nomos and Psephisma in Fourth-Century Athens, en Greek, Roman and Byzantine Studies, 19 (1978) 4, pp. 315-330. 
-- Nomos ep' andri in Fourth-Century Athens: On The Law Qoted at Andocides 1.87, en Greek, Roman and Byzantine Studies, 57 (2017) 2, pp. 268-281.

-- The athenian democracy in the age of Demosthenes: structure, principles, and ideology (Norman, University of Oklahoma Press, 1999).

-- The sovereignty of the People's Court in Athens in the fourth century B.C. and the public action against unconstitutional proposals (Odense, Odense Universitetsforlag, 1974).

Harris, Edward M., The rule of law in action in democratic Athens (New York, Oxford University Press, 2013).

Harrison, A.R.W., The law of Athens: procedure (Londres, Oxford University Press, 1971).

Johnstone, Steven, Disputes and democracy: the consequences of litigation in Ancient Athens (Austin, University of Texas Press, 1999).

Kelsen, Hans, Jurisdição constitucional (São Paulo, Martins Fontes, 2003).

Kremmydas, Christos, Commentary on Demosthenes against Leptines (New York, Oxford University Press, 2012).

Lanni, Adriaan; Vermeule, Adrian, Constitutional Design in the Ancient World, en Stanford Law Review 11 (2011) 6, pp. 907-949.

LanNI, Adriaan, Judicial Review and the Athenian 'Constitution', en Harvard Public Law, 21 (2010) 10, pp. 236-240.

-- Precautionary Constitutionalism in Ancient Athens, en Cardozo Law Review, 12 (2012) 31, pp. 904-909.

LEWIS, John David, Early Greek lawgivers (s.l., Bristol Class, 2007).

Lipsius, J.H., Das attischeRecht und Rechtsverfahren (Leipzig, O.R. Reisland, 1905).

Lopez Eire, Antonio, Demóstenes: estado de la cuestión, en Estudios Clásicos, Consejo Superior de Investigaciones Científicas 20 (1976) 78, pp. 207-240.

MacDowell, Douglas M., The law in classical Athens (New York, Cornell University Press, 1986).

Manin, Bernard, Deliberación y discusión, en Revista Saap, 2 (2005) 2, pp. 239-256.

MONTESQUieu, El espiritu de las leyes (Madrid, Istmo, 2002).

Ober, J., The Athenian revolution: essays on ancient Greek democracy and political theory (Princeton, Princeton University Press, 1999).

Palao Herrero, Juan, El sistema jurídico ático clásico (Madrid, Dykinson, 2007).

Pavón Torrejón, Pilar, La cárcel y el encarcelamiento en el mundo romano (Madrid, CSIC, 2003).

Petrie, Alexander, Introducción al estudio de Grecia (México, Fondo de Cultura Económica, 1995).

Reduzzi Merola, Francesca, Il giudizio di costituzionalità nell'esperienza greco-romana, en Annali del Seminario Giuridico dell'Università di Palermo (2008) 52, pp.43-51.

RoTHCHILD, John, Introduction to Athenian Democracy of the Fifth and Fourth Centuries BCE, en Wayne State University Law School 32 (2007) 7, pp. 3-41.

SARTORI, Giovanni, Constitutionalism: a preliminary discussion, en American Political Science Review, 56 (1962) 4, pp. 853-864.

Schmitт, Carl, O guardiāo da constituição (Belo Horizonte, Del Rey, 2007).

SCHWARTZBERG, Melissa, Was the grapheparanomona form of judicial review? Conferencia publicada en Cardozo Law Review, 34 (2013), pp. 1049-1062.

SEllers, Mortimer; TOMASZewsKI, Tadeusz; The rule of law in comparative perspective (Baltimore, Springer, 2010). 
Sinclair, R.K., Democracy and participation in Athens (New York, Cambridge University Press, 1933).

Todd, Stephen; Millet, Paul, Law, society and Athens, en: Cartledge, Paul; Millett, Paul; TodD, Stephen, Nomos: Essays in Athenian law, politics and society (Cambridge, Cambridge University Press, 1990), pp. 1-19.

Todd, S. C., The shape of Athenian law (New York, Oxford University Press, 1993). Uribe Arzate, Enrique, El Tribunal Constitucional (México, UAEM, 2002).

VANECIANO, Gustavo, La discreción judicial en los jueces griegos arcaicos y el problema del precedente, en: AmES, Cecilia; SAGRISTANI, Marta (comp.), Estudios interdisciplinarios de historia antigua (Córdoba, Encuentro, 2007), I, pp. 305-312.

VAZ de Lima FilHo, Acácio, O poder na antiguidade: aspectos históricos e jurídicos (São Paulo, Saraiva, 1999).

YunIS, Harvey, Law, politics and the graphéparanomon, en Greek, Roman and Byzantine Studies, 29 (1988) 4, pp. 361-382. 
